\title{
In Conversation with Vicki Kirby: Deconstruction, Critique, and Human Exceptionalism in the Anthropocene
}

\author{
Vicki Kirby and Marc Higgins
}

\section{Using AND Troubling the Anthropocene}

Marc: We find ourselves in strange and unprecedented times. As you state, the "most pressing questions about the achievements of science or about environmental dramas that threaten species diversity and human survival require stories that are heavily reliant on scientific evidence for their political credibility and gravitas" (Kirby, 2017, p. 7, emphasis in original). Science, and in turn science education, present themselves as both poison(s) and panacea(s) in the ways in which we can both imagine and enact our response-ability to this contemporary moment that is often referred to as the Anthropocene.

Within your 2018 piece, "Un/limited Ecologies", you make this argument both explicitly and carefully. Particularly, through a beautiful reversal and (re)opening you ask us, in this moment of urgency in which we are politicizing taken-for-granted understandings of ecologies, what it might mean to understand politics as ecologies: finding fissures in the statement that the current moment is caused by humans and the ways in which this admission of culpability might mask more than it reveals.

V. Kirby $(\varangle)$

School of Social Sciences, The University of New South Wales, Sydney, NSW, Australia

e-mail: v.kirby@unsw.edu.au

M. Higgins

Department of Secondary Education, University of Alberta, Edmonton, AB, Canada e-mail: marcl@ualberta.ca 
Could you speak to the ways you are witnessing irruptions of anthropocentrism in the ways it is resisted and why these particular slippages are significant in how we conceptualize and mobilize our responses to the Anthropocene?

Vicki: My answer risks being a bit long-winded for two main reasons. I'd like to say something about how I arrived here, because these concerns take me back to my early studies in anthropology which in some ways inform my current position. And not unrelated, the knot of investments that preserve the identity of Anthropos as an analytical departure point in most of the literature involve investments and assumptions that I want to interrogate further. So, to begin with the discipline of anthropology, it seems fair to say that it strives to document and understand the myriad behaviours, mores, and beliefs that reflect what it is to be human. There is surely an irony in the perception that the unitary essence of human exceptionalism is secured in the sheer diversity of societal and cultural expressions; indeed, our ability to interpret the world in comparatively idiosyncratic and inventive ways is said to be remarkable among other animals, as culture effectively generates our world as a meaningful place. When I began my studies I was aware of the diversity of sexuality and gender roles across different societies and histories, and perhaps more compellingly, I had always been exercised by the vagaries of moral and ethical belief across cultures and even historical moments within the "same" culture. And yet the appeal of this inclusion by exclusion, namely, the belief that we fabricate a world rather than respond to its enduring and universal truths, became something of an obstacle as my research progressed. Was there really no access to a reality outside or before human mediation? This is how the question is conventionally configured, as if two quite separate systems, or entitiesnature and culture-pre-exist their possible encounter and interaction. As I describe it above, we tend to think of nature as a steady and stable sameness that endures, its truths unchanging, whereas cultural insights are mutable and always shifting. But what are the implications of refusing this division and its attending logic?

I was fascinated by the riddles that anthropology generated but also taken aback by the defensive rhetoric that surrounded them. Yes, there was an implicit commitment to cultural constructionism well before the mantra took hold in emerging disciplines such as cultural studies. However, the appeal of fieldwork's immersive cultural experience-you can't presume to understand a society from the outside-assumed quasi-scientific credentials through its detailed evidence gathering "on the inside". It was as if cultural relativism was both true and false, as if the inherent integrity and enclosure of a particular culture prevented access even as it revealed its mysteries to a specialist few. If we concede that we inherit an invisible legacy of accumulated interpretations and subjective prejudice that misidentifies our particular cultural/historical inheritance as a universal, shared, and self-evident reality, then where are we standing when we interpret other cultures? In anthropology, the threat of cultural relativism seemed grafted into the discipline's every assumption, and 
yet the practice of ethnography erases the question of how these purportedly separate systems of "making sense" are translated by, and into, something apparently "other", foreign and external.

I think these questions about the unifying term "culture" and its capacity to accommodate myriad modes of being that are considered separate yet strangely inseparable and entangled (hence, their translatability), rehearse larger conundrums regarding the special status of human identity versus its non-human others. To explain this, we tend to align being human with the unique ability to "world" a world through language and representation. Consequently, to be human is to be cultural, to reinvent our world to reflect specific human needs and understandings. However, the elephant in the room is nature; not the "nature" generated within the hermeneutic circle of cultural interpretationnature as a cultural artefact that we misrecognise as what is not culture-but a nature whose identity, at least according to cultural construction, pre-exists human arrival and escapes representation. This escapee nature surely complicates the truth claims of the sciences because a history of political (cultural) prejudice inevitably informs all of human endeavour, albeit to different effects. And if scientific inquiry can't remain immune from the cultural life that produces it, is the belief that nature and culture are two quite separate systems of operation still plausible? After all, we board planes that provide us with rapid transport, take medications that cure myriad ailments, and rely on algorithms to deduce forensic and scientific evidence. If we invest in the hermeticism of cultural construction, then how can the models and representations forged in the sciences presume any working purchase whatsoever?

One way into the conundrum is to query any commitment to the initself of culture, whether defined against nature, or whether conceded internal variation in the myriad cultures whose different locations and expressions a more traditional anthropology tried to capture and define. The implication here is that an escapee nature, one which I previously described in terms of its "enduring and universal truths", will also lose its referential status as a foundational "something" against which change can be measured. No longer outside and other to culture, it reappears as a force and energy intrinsic to being anything, including being human. And this is where things get interesting. Instead of assuming that to be human is to be radically different and separate from the world, a belief that understands the activities of science in terms of a tripartite division between human subject, intervening model, and object of analysis, the ability to scrutinise how the world works, to invent technologies and languages as instruments of inquiry, are no longer unique to being human. The inquiring subject now manifests in worldly form, and all its possible individuations (of itself) appear as specific manifestations of a larger field of agentic forces. This way of thinking finds the subject enfolded with/in the object; however, this is an auto-affection that is inherently heterogeneous and diffracted. Just as anthropology divides culture into myriad individuations, assuming their differences are somehow both separable and yet inseparable (such that the opposition no longer holds), we could say that the world 
individuates itself infinitely, and yet these differences from and within itself (technologies) are not as autonomous and separate as they appear, but rather, articulations of what Jacques Derrida calls "systematicity". Although various authors in critical theory have emphasised this sense of a shared world, a world in which relationality gives us our respective identities, I want to nuance this assertion to better explain a more counterintuitive sense of relationality. "We are part of the world" is now a standard reminder that we are not innocent or separate by-standers in regard to the world's well-being. And yet this sense of "the part" fails to capture the ontological complicity of individuation. For me, we are not so much a component, or individual member of a larger world picture, one that might be likened to a jig-saw puzzle where each piece is local and situated ${ }^{1}$ while still necessary to the whole picture's possibility. In other words, I am not trying to evoke an assemblage of parts, but rather, a sense that any "one" part is always/already an articulation of and by the whole. Thus, the limits that secure "one" identity are diffracted through and by the whole, both local and non-local at the same time.

If we generalise such formative complicities then there are only intra-active ecologies, congealings of spacetime whose apparent differences are transversally implicated. When I liken political positions and ideologies to ecologies it is within such a framework of profound intra-dependence. This means that culpability is a fraught notion because causal forces don't arise in a single origin or author: if identity (of whatever sort) is internally diffracted, then we begin with structural entanglement rather than clean and isolated identities. This is not to endorse the rejection of, say, anthropogenic climate change or to celebrate political quietism, as if one position is as good as another. But it does question the identity of Anthropos as an autonomous agent, able to realise his intention to destroy or remediate, as if it is his decision to make. For example, the profligate and violent behaviour of humans in our squandering of resources and indifference to the consequences is a comparatively easy criticism to make. This is a confession, a mea culpa. And yet there are questions to be asked about such a gendered and racialised understanding of power that identifies the other, nature in this case, as inherently passive, incapable, the dumb and helpless victim of human action. To admit that we are subject to forces that far exceed our ability to control them, and that our individual identity and agency is a fractured ecology of seemingly alien chemistries and "creatures", such that "nature speaks us", leaves us feeling uneasy. I'm going to suggest here that life/nature is always out of step with itself and in constant argument about

\footnotetext{
${ }^{1}$ Much cultural analysis has countered the pretentions of a universal, god's-eye-view perspective with the modesty of "situated knowledges" that are experientially grounded and therefore, more politically and ethically pertinent. Indeed, science has often been seen as the culprit that denies its embodied location in the rush to secure its status as objective, repeatable, universal. Although these have been important interventions, the separation of the universal from the situated and local, the objective from the subjective, or the notion of what is rational and abstract from what we claim as embodied experience, is considerably more confounded than a choice of sides can explain.
} 
what its myriad identifications imply, demand, secure or prevent. If there is no stable integrity or final reference that can still this dynamic, neither God nor a transcendental truth, then our arguments will need to be alert to the flows and vagaries of our shared situations: how we engage specificity can matter profoundly.

\section{Situating ANd (Re)Committing to Deconstruction at the Ontological Turn: "What if Culture Was Nature All Along?" (Kirby, 20I7)}

Marc: As Latour (1993) frames in We Have Never Been Modern, the ecological problems that we face and attempts to account for and be accountable to are at once cultural, natural, and deconstructing; in turn the ways in which we formerly relied on bracketing out nature to make strong cultural claims (e.g., sociology), bracketing out culture to make strong naturalistic claims (e.g., science), and rupturing the stability through which truth claims are made (e.g., deconstruction) might no longer be sufficient.

However, because deconstruction subverts often taken-for-granted assumptions about mediated access to an external natural or cultural reality (and, more recently, subverts the binary distinction between the two, as you do in your work) by subverting their stability, it is often and always already unwelcome within the fields of science and science education. Or, as Barad (2011) states, Derrida is "the science warriors' darling stand-in for all that is wrong with the humanities" (p. 448).

What might it mean to commit to deconstruction in fields wherein it might already be a precarious position from the get-go? Or, how do you leverage that ambiguity towards productive ends? Further, in this contemporary moment, what can deconstruction (after Derrida) offer, perhaps not as corrective, but as productive orientation towards responding otherwise?

Vicki: If we set up an opposition between what science claims to achieve versus the value of insights from the humanities and social sciences-and I agree that such divisions are routine, as the pragmatic concern in your question makes plain-then we inevitably find ourselves in a structural impasse. How to reconcile entirely different and even contradictory truth claims, modes of valuation and methodology in these different endeavours? Is the only response to insist that "the two cultures" are irreconcilable, and leave it at that? I suppose my own strategy is to question the ways in which we quarantine these different practices and explore what might be at stake in maintaining their respective autonomy. Feminism, for example, was especially interested in the phenomenon of hysteria in the late eighties because it appeared that political discrimination could be somatised (Gatens, 1983; Irigaray, 1985). However, Elizabeth Wilson made the important point that much of this commentary, despite its explicit assault on the nature/culture division (which carries myriad discriminatory associations), failed to ask how biology could "perform" these 
politically charged symptoms (stigmata, hysterical blindness, dermographism, etc.) (Wilson, 1999). Today, scientific evidence in epigenetics tells us that the effects of difficult social and psychological circumstances are inheritable across generations, so perhaps ironically, it is science that questions the definition of culture as the other of biology. Brain plasticity is another example that illuminates how cultural and social activities are cerebrally registered. And there are arguments coming from the sciences that "the knowing subject" is an impossible fiction. Indeed, myriad examples support what we might call post-structural insights into the complexity of reality. ${ }^{2}$

However, when you get down to the finer descriptive details in many of these examples there remains an almost automatic need to locate agential efficacy in culture, as if that's the only way to understand the direction of these dynamics. Even the term "epigenetics" implies it, something I hadn't realised until I was brought up sharply by a conversation with Astrid Schrader, a scholar whose work in deconstruction and science studies is full of intriguing challenges and insights. ${ }^{3}$ I recall her saying rather matter-of-factly, which only underlined the point, that the "epi" in epigenesis that signifies supplement, addition, something nearby (which is how we think of culture's relationship with nature) was redundant and misleading. "It's just genetics" she said, reminding me that, because the gene isn't closed, there is no addition. Although the causal logic from culture to nature tends to remain intact-and the sciences and humanities are both invested in preserving it-I've always found that students are especially intrigued by this particular riddle if you guide them through its surreal logic. How, for example, does biology-meatread the variety of culture's messages and enact its corporeal theatre through tissue, blood, nerves, chemical arrangements, and so on, if meat is deaf to the literacies of culture? Put simply, if it isn't in the nature of biology to speak, to read, to think and metamorphose, then how do we achieve these behaviours? And why do we assume that this "we" that acts is not a biological dynamic?

I guess I'm trying to say that an intervention that strives to bring the humanities and sciences into some kind of dialogue or disruptive displacement has myriad sites of potential engagement because there is cross-over, dispute, and ambiguity on both sides of the ledger. Yes, there may be opposition from the sciences about the value of something like deconstruction just as there is in the humanities, but that's because "deconstruction" is so misunderstood. Why brandish that particular banner if your audience has already turned the page? For example, you cite Bruno Latour, a thinker whose ethnographic work has significantly reconfigured how a scientific truth can emerge from a cacophony of forces. The scientific apparatus for Latour is arguably a field

\footnotetext{
${ }^{2}$ As references are myriad, a quick scan of the cover stories from New Scientist surely underlines the point. I mention just two. "Reality: The Greatest Illusion of All" (August 2019); "Memory: The Exquisite Illusion That Creates Our Sense of Self" (October 2018).

${ }^{3}$ For a fascinating argument about the ontological shapeshifting of life forms that is representative of this thinker's innovative perspective, see Schrader (2010).
} 
of involvements whose distributed agencies and networks include the nonhuman. However, despite enabling a more comprehensive understanding of truth production and what constitutes evidence, Latour remains aggressively dismissive of deconstruction, which he interprets as a destructive enterprise, smugly returning us to the prison house of language- "a brain in a vat"-that is hermetically sealed against the material world that he wants to investigate (1999a, 2003).

Although this is an all-too-common misreading I doubt that a corrective will achieve very much because Latour's appeal is his apparent ability to resolve a problem. So perhaps a more effective strategy that Derrida himself recommends (1994-1995) might be to read Latour's achievement grammatologically, acknowledging his insights while magnifying and extending their implications further. Let's take "Circulating Reference: Sampling the Soil in the Amazon Forest" (1999b) as our example. Latour provides us with a moving and evocative image of the intrication, or sociality, of different people, languages, plants, soils, make-shift technologies, and idiosyncratic behaviours, all of which are nevertheless "reduced" into words on a page, letters that translate the Amazon forest into what Latour holds in his hands at the end of the exercise. Questions about translation, indeed, transubstantiation, are alive in this scene, and the notion of reduction as "less than" is overturned and made strange, for the words evoke a vastness, a worlding, whose reference has evidential leverage. Latour brings genuine wonder to this scene of radical metamorphosis: how did all these different ontologies prove so intimate in outcome? And how could the world be here, on a page? I think we can redeploy the terms and investments in Latour's argument to offer a more deconstructive reading, shifting his rigid (albeit disavowed) commitment to anthropocentrism and the politics of aggregation as we go. Remaining faithful to deconstruction's canonical format, vocabulary, and disciplinary commitments can elide the grammatological mysteries and fascinations within texts that we would otherwise criticise and reject too quickly.

Marc: A recurring theme in your work is the question of What if Culture Was Nature All Along? through which you address how deconstruction might differently respond to and disrupt the nature/culture binary. Of particular importance, your work explicitly takes up what it means to consider as coconstitutive nature/culture without reverting nature to a pre-critical status; or, along Spivak's (1976) line of thinking, that "to make a new word is to run the risk of forgetting the problem or believing it solved" (p. xv) through reproducing the problem elsewhere, albeit differently; displacing rather than disrupting. Significantly, and repeatedly across your scholarship, you call us to come-to-know the philosophical history which has come to inform this recent turn so that we do not differentially repeat ourselves: a trajectory from humanist, to anti-humanist, to post-humanist approaches.

Could you carefully take us through, albeit with broad strokes, the trajectory through which you understand the relations between nature, culture, 
and representation as they are articulated within humanist, anti-humanist, and post-humanist approaches?

Vicki: Again, I think I'll have to answer your question in a rather roundabout way because if I'm being true to the detail of what motivates my own practice I'd have to say that this notion of "co-constitution" has always bothered me. In fact, I've never really liked the corollary expression, "natureculture", either. My reservations might sound pernickety given the routine use of these notions in cultural and critical theory circles. But as we are getting to the pointy end of what is at stake in these arguments I should take the opportunity to clarify my position. This will also allow me to better explain why I've glossed Derrida's "il n'y a aucun hors-texte" ["there is no outside (of) text"] as "there is no outside (of) Nature". First of all, you rightly note that my aim is to leverage nature out of its pre-critical position as "the before" or "primordial", that material "stuff" that lacks the more evolved capacities of language, agency, and intelligence. Such assumptions rest on a circumscribed concept of identity, because even if we acknowledge the genesis or emergence of something we tend to assume that this processual dynamic is in the past, before identity "set" into something unique and locatable. However, I'm not trying to give nature a Latourian dynamic whose extent, by definition, will nevertheless remain circumscribed (because nature for Latour isn't culturehe remains committed to the human as master of the dance). Instead, I want this sense of one plus one to collide and fracture, not into ever tinier aggregate parts, but something whose mysterious involvements defy simple division. In my teaching, I used to evoke this sense of an originary energy that remains alive and ubiquitous "throughout" a field, or system, by using "magic-eye" images that were popular some decades ago. You look at a mess of electric colours and lines, you relax your focus, and suddenly you see a 3-D vase of flowers, a heart inside a box, or perhaps three dolphins. My aim was to underline that these images are generated from within the same frame, that what appears to come second is already alive with/in "the original". This difference without addition, a discrimination that requires no distance, complicates the concept of difference as something straightforwardly other and elsewhere. For me, "nature-culture" looks too much like a solution, an amalgam whose respective differences remain identifiable. And just as Spivak warns, we see this recuperative tendency at work in the appeal of the cyborg and in earlier versions of feminism's critique of the Cartesian mind/body split. Such interventions can seem to resolve a problem when they underline inseparability and interdependence and yet they remain committed to difference as an amalgam. The popularity of supplementary logic is that the difficulty we are engaging is perceived as a problem to be solved rather than an enduring and constitutive dynamic. Making these differences adjacent might feel more satisfying because hierarchies are deemed to be bad, avoidable, wrong. However, to read is to hierarchise, to learn, evaluate, and adjudicate involves hierarchies, to reject a binary for an apparent non-binary is to hierarchise (and inadvertently binarise). If we just say yay or nay to a binary, as if we are confronted with a 
moral dilemma, we remain blind to the incestuous structures, the perversity and impurity that discovers another perspective within the one that seems to refuse it.

With these considerations in mind, my aim is to reframe what is conventional in our thinking by acknowledging how "systematicity as such"-a heterogeneous "unity" wherein "firstness", or "originary différance", remains ubiquitously at work-can accommodate myriad perspectives within one perspective, a bit like a nesting of Russian dolls but without distinct, internal borders that neatly separate one perspective from the next. To refer to this transubstantiating energy as "nature" challenges what is routine in humanist, anti-humanist, and even many post-humanist assumptions regarding human exceptionalism; developmental narratives of progress and increasing complexity; as well as language and cultural representation as relatively recent and unique technologies. Without an absolute referent against which to define, locate, and identify anything in absolute terms, the historical framing of humanism against anti-humanism and post-humanist approaches is as useful as it is misleading. Where, for example, should we place Spinoza, or Leibniz, because their writings are in many ways exemplary of deconstructive criticism, and yet deconstruction had yet to arrive ... or was it already at work?

Marc: This last move is not a small pivot and shift. As we collectively move towards considerations of ontology you invite us to use and trouble Butler's criticism of particular cultural uses of "natural facts" as they still stand today: “"natural facts' are always informed by cultural bias" (Kirby, 2011, p. 94). Further, this is "one of the most important contributions that scholars such as Butler have made, ... any return to the question of Nature will need to accommodate or reconfigure such insights rather than put them aside" (p. 94). Yet, to consider the ways in which matter comes to matter, you state that this is "not to suggest that we need to 'get real' and add Nature's authorship to this strange text, as if Culture's inadequacies might be healed with a natural supplement” (Kirby, 2011, p. 13).

This question bears coming at it once more, differently: particularly because, as you mention elsewhere (Kirby, 2017), the insight that "relationality is not mediation; it is not an in-between entities" (p. 11, emphasis in original) often gets lost. Could you elaborate upon this?

Vicki: This is a wonderful question that allows me to dilate on what must seem like a contradiction in my commitments. Why would I want to respect the oppositional logic that underpins Judith Butler's understanding of nature, the body, and matter if elsewhere my aim is to undermine this way of thinking? Can we get out of this conundrum and resolve its stickier inconsistencies, or does this sense of being caught up in the very thing we want to question and refute set the scene for a different heuristic, a different understanding of what this new buzz word, "entanglement", might involve?

Let's begin with Butler. I was approached by Continuum to write Judith Butler: Live Theory (2006), and as I knew Butler's work well I was confident that I could despatch the task quickly. However, as I surrendered myself 
to the intimate detail and pulse of her arguments I realised how closely her commitments tracked with my own, even though her departure point and its associated assumptions-namely, there are no outside cultural (human) representations of a world whose extra-linguistic reality remains inaccessible to us-inadvertently recuperates the very binary divisions and circumscribed identities she strives to complicate. However, this is not a simple mistake that can be put aside. I share Butler's appreciation that "structure" and "system" are organisational, allowing culture to constitute entities "from within itself", that is, that "the how" of identity formation is inherently systemic and entangled. Butler offers a compelling argument that illuminates why nature is not the other of culture; why nature is not a passive, feminised, and racialised "primitive" whose difference provides the reference point against which masculinism, racism, and today, anthropocentrism, might justify their superiority and developmental complexity. However, to name and enclose that systematicity as properly human/cultural commits Butler to notions of identity and integrity that undermine and contradict the overall direction of her argument: power becomes "power over", its productivity largely negative. The sign becomes an entity within a context of different/other signs rather than an articulation of that context with no outside "itself". Nature, now under erasure, reappears as radical alterity, "something" that pre-exists human arrival, language, and mediated representation. To make the point succinctly, Butler has no way to even consider that the nature she excludes from the chattering activity of cultural production has the capacity to re-present itself as cultural production.

As my position vis-a-vis Butler involves an acknowledged intimacy my strategy was to follow her logic to the letter as best I could and ask questions when she seemed to depart from her own insights: what justified the integrity of the boundaries and limits she presumed when her entire argument called integrity of any sort into question? How could she justify difference as a gap between entities as if these entities pre-exist their ongoing manufacture through différance; why does she assume that the body that speaks and reads is itself illiterate, returning us to the Cartesian subject whose residence is necessarily outside or other than the body/nature? I tried to ventriloquise her arguments as if I were inhabiting them, wearing them like a piece of clothing but to very different effect.

The reason why arguments that privilege "cultural construction" are, to my mind, not simply mistaken - at least, not in the conventional sense that might hope to repair an omission or correct an error by adding something presumed to be absent-is that "systematicity" complicates this logic. For example, when I displace the conventional reading of "no outside textuality" with "no outside nature", I haven't really added anything. And yet the systemic implication of what we understand as "productivity" is radically transformed, and all those entities or capacities regarded as primordial, "the before", begin to manifest and resonate throughout the system, and vice versa. 
These are really difficult and subtle concepts to negotiate, and Derrida's insistence that identity is not secured by an "in-between"-because there are no entities that would anchor that sense of spacing/timing-is a challenge that continues to exercise my attentions. How to represent this extraordinary insight when conventional understandings of representation and perception "work", at least on the surface, by denying these entangled ontoepistemologies? I think it's a question of timing. If I think of my students who are naïve empiricists when I meet them-the world is what it seems, questions of phenomenology and subject formation are entirely unknown to them, the "rational subject" is, indeed, "the one who knows", language is a thing that we acquire, a thing that separates us from everything that is not human-I can only disrupt that worldview and allow a more generous and complex appreciation if I work with their convictions and interrogate their hidden reasoning. A bit like my strategy with Butler, I need to challenge their commitments by using the logic that makes sense to them, because on closer inspection, that same logic will manifest errancies and slippages whose disavowals and defenses can prove insightful. I'm not really introducing something new that isn't already at work within their very own worldview. To this end, what might make the difference in providing those students their aha! moment could be an excerpt from a science journal, Butler's work, or even Descartes', something apparently conservative and wrong. Because surely, all these texts are already alive to each other, open to different interpretations and perspectives. Different worldings can emerge, but from within one perspective rather than as separate alternatives.

\section{Critical Consequences: Critique After the Critique and Subject of Critique}

Marc: The consequences for the earlier (and above) are multiplicitous: one which you continue revisiting in your scholarship is what it means to engage in critique after (or perhaps more within) the critique of critique. Or, to be more precise, that criticality stemming from the realization that critical negation has "run out of steam" (Latour, 2004). As you state, "critique is a messy business that can surreptitiously recuperate and affirm what it claims to reject" (Kirby, 2018, p. 122).

Can you speak to the importance of attending to snags and irruptions not as flaws to point out in ways that dismiss the entirety of the argument, but rather as grammatological opportunities: openings to deconstruct the textuality of that which lay before you to pursue meaning-full-ness? Also, why is it significant to engage an affirmative critique that emerges out of proximity rather than distance?

Vicki: My previous answer illustrates something of the manoeuvres that might promote a more affirmative practice, but it's worth emphasizing this issue because negative critique carries many traps and pitfalls that can ambush 
the wary as well as the unsuspecting. The perverse antics, errancies, and unpredictabilities of intratextuality (systematicity) aren't problems that fall away and disappear once diagnosed, nor are they resolved with a change in approach that reads "generous" as a call to add what was previously excluded. The spatial logic that underpins this apparent choice between an inside or an outside-whether to include or exclude what is absent or missing before we "get generous"-turns an ontologizing, structural entanglement into a problem which a sovereign subject, presumably situated outside this same entanglement, could resolve. A more affirmative reading works with an understanding, however, fragile (because this is not a knowledge that is separate from what constitutes our own being-in-the-world), that the implications of systemic complexity are already at work in all arguments. Given this structural complicity a grammatological practice isn't better because it includes more than another practice, or because it affirms rather than rejects, or because it doesn't narrowly restrict its focus. The point here is that even a very focused argument, or one with a perspective that we might deem risible and patently wrong, is nevertheless an expression of this same, shared, involvement. An important clarification, however, is that "shared" doesn't commit us to a soup of sameness, for what is "common" is an ever-changing field of crossreferential forces whose internal differences are "in touch" even when they appear separate. An illustration of how this difference within apparent sameness might work can be seen in language use. Every individual inherits a mother tongue, or langue. And yet we know that every individual speaks that same langue in a unique way (parole), deploying a particular vocabulary, relying on certain rhetorical structures, slang expressions, and local idioms whose repeated patterns constitute a very specific signature of language use. Given this, we could liken a society to the collective aggregation of these independent voices which together express their individual intentions and personal perspectives. Such a view conceives of society as a federation of individuals where each person is an autonomous agent, the sovereign source of their actions and choices. However, the analytical division between society and the individual can leave us wondering about the relation between the whole and its part, or how an individual becomes social if they are not socially primed to begin with.

If we begin our analysis with a sense of an entangled "whole", an implicated, self-reflexive force field, then any "part" is not so much an entity in a context - in this case, an individual in a society — but rather, an individual whose specificity is a particular expression of that "same" society. Returning to our language example, we could say that langue individuates itself, or that langue paroles. But why should this matter at all? The relevance of this latter description is that it allows a robust understanding of specificity, not by circumscribing identity as an island surrounded by a context (an outside identity), but by an appreciation that the system reconfigures itself in specific (individual) ways. In other words, the specificity of parole isn't isolated and 
autonomous but deeply embedded in and through those entities that appear other and elsewhere.

In sum, despite renewed awareness of the consequences of negative critique, the critique of critique can operate as yet another opportunity to leverage (while disavowing) judgmental self-righteousness. It's as if the left hand doesn't know what the right hand is doing, and we are all persuaded by this naïve belief that we can truly take our distance. I recommend Ash Barnwell's (2017) wonderful engagement with this dilemma in "Method Matters: The Ethics of Exclusion". To take one simple illustration from her argument, she returns us to Latour's irritation with critique as "essentially limited and destructive" (p. 30), citing his comparison of critique with the destruction of a hammer. According to Latour, a hammer can undo, but it can't compose. However, Barnwell's response is, as she describes it, "prosaic""hammers create and build homes, repair cars after panel beating ... the list is endless: destruction from one perspective is hope and restoration from another" (p. 30). It is this paradox that sees one identity, position, or methodology within another-such that "their" respective differences are strangely confounded, that to my mind is more politically and ethically provocative and dare I say true, than those arguments that seek to make a virtue out of distancing themselves from the very errors which they unwittingly recuperate and promote.

Marc: Another of the recurrent themes within your work is the notion that Cartesianism is not so easily remedied. Not unlike Butler's (2005) line of questioning "does the postulation of a subject who is not self-grounding, that is, whose conditions of emergence can never be fully accounted for, undermine the possibility of responsibility and, in particular, of giving an account of oneself?" (p. 19), you invite the question of whether a decision and its associated notions of responsibility and forethought can exist without Cartesian notions of self-possession. Particularly, after the epistemological uncertainty of the subject as posited by Butler, you offer an ontologically indeterminate subject as the location from which critique emanates.

What might it mean to take seriously the notion that if the subject is not separate from its object, the task of criticality too becomes less self-evident?

Vicki: Let's set the scene in order to appreciate the question's difficulty. Responsibility and accountability presume a sovereign subject who has full command over his actions and is "at one with himself" such that he can realise his intentions. ${ }^{4}$ In other words, how he acts is his choice, his decision, and this allows us to apportion blame and determine culpability. Although this is surely a pragmatic requirement for a society's survival — and I think your question is attentive to this necessity-this doesn't change the fact that the sovereign subject as we conventionally understand him is more fiction than fact. We know that poverty, racial and sexual discrimination, and other forms

\footnotetext{
${ }^{4}$ I've chosen to use the masculine pronoun to acknowledge the masculinism that structures these seemingly straightforward and universally applicable logics.
} 
of social denigration and suffering have deleterious effects on an individual's life chances and life choices. Indeed, the very notion of choice seems thin and rather shabby when considered against social inequality and deprivation, and this, against a backdrop of exploitation both domestic and global. However, the fiction of the sovereign subject isn't explained by social difficulty alone. The point isn't that some people aren't in a position to exercise choice, enterprise, and initiative whereas others are (although this is surely an important consideration for how a society explores the significance of opportunity and agency).

In respect to the larger question of subject formation you don't need Freud or more contemporary psychoanalytic insights to tell you that we are all of us motored by unexamined and uncontrolled fears and desires that drive and direct our behaviours. How often, for example, do we narrate a story and a friend who shared the experience counters with an entirely different interpretation; or we are forced to the painful conclusion that our positive experience of a relationship was sadly misconstrued or made foolish by the unexpected outcome of events? The evidence suggests that we remember in interested ways and that to a significant degree we live our lives in disavowal. And we do this in good faith, not knowing that the archive of our memories can prove marvellously creative. Unfortunately, the awkward apprehension that the truth can't be determined once and for all, or that the subject is duplicitous, even self-deceiving, feels like a cruel insight that leaves us with nowhere to turn.

I've tried to elaborate why the decision to say yes or no to something via the routine manoeuvres of critique can refuse to acknowledge the myriad involvements that inform the very "thing" that is in question. It's like asking, "Do you believe in God?" and being satisfied when your interlocutor responds with a yes or a no. What both answers leave intact and uninterrogated, despite their apparent difference, is the object of the question-not just the fact of God's being and possibility, but the more general mystery of being and existence that confronts us all, regardless of religious belief. To my mind, the Butlerian perspective shares something of this avoidance even as it seems to target the question of the subject by underlining its impossibility, its deficiency, incapacity, and self-deception. However, it is a sovereign subject, an "I, me" who is called upon to admit their failings and know their deficiencies.

I'm more challenged by the way Derrida broaches this "self-capture" in The Beast and the Sovereign (2011). He is clearly impatient with confessional declarations about peccability and insufficiency because they actively affirm a subject whose sovereign identity is made manifest in guilt, acknowledgement, and a recuperated (if surreptitious) appeal to enlightened responsibility. Although Derrida doesn't reject this approach outright, indeed, he refuses to refuse its motivational direction entirely, he nevertheless mounts a counterintuitive tactic that complicates its conceptual investments while not dismissing them out of hand. Importantly, the enigma of the subject or "who" remains open for Derrida, and in such a way that it appears displaced, a seemingly ubiquitous authorial presence whose enigmatic identity haunts his entire argument. I've 
tried to explain how this sense of displacement and breadth (systematicity) might be alive in/as the unique singularity of individuation by referring to the frontispiece of Thomas Hobbes' Leviathan, a lithograph of the sovereign, sword and sceptre in hand, by Abraham Bosse. On close inspection we find that this unified subject, this body of supreme and sovereign power who appears outside the law (inasmuch as he pronounces it), is already hostage to a populace, broken up and into by myriad vociferous divisions, ventriloquised and strung through like a dummy or marionette, the agency of this "I, me" invaded, peopled. Through such a reading, l'état c'est moi takes on a very different complexion that complicates individual agency, blame, and causal explanation. The point isn't that there is no subject, no sovereign agent simpliciter. As Derrida explains,

In a certain sense, there is no contrary of sovereignty, even if there are things other than sovereignty... even in politics, the choice is not between sovereignty and nonsovereignty, but among several forms of partings, partitions, divisions, conditions that come along to broach a sovereignty that is always supposed to be indivisible and unconditional. (2011, Vol. I, pp. 76-77)

What I take from this is that we need to think again about what we mean by control, and whether either denying or acknowledging the possibility of sovereign responsibility, the authority of an "I, me", can actually do justice to the intricate political complicities that compromise such adjudications. I don't see this as an excuse for political quietism, but rather a call to think again in ways that aren't complacently routine. Although we still have to decide and take a position in regard to specific political and ethical concerns, a more robust acknowledgement of the forces that "author" a decision might allow us to better appreciate why positions aren't as stable and fixed as they might seem and why any one response might be replete with myriad perspectives and even contradictory interests.

\section{Response-Ability and/At the Anthropocene}

Marc: Not that the logics of containment or closure could come to contain the arguments made here, revisiting the guiding question of this interview, how might some of the arguments made earlier (re)open the ability to respond to this particular moment that we call the Anthropocene?

Vicki: The concept of "human exceptionalism" describes our species' unique intelligence and creative capacity, whether for calculating purposes and self-interested goals-in which case we are described as perpetrators and misfits, destroying the natural order-or inventive change agents who can remediate previous mistakes and even improve and augment our natural inheritance. By reconfiguring Derrida's "originary différance" as "originary humanicity" I wanted to destabilise the automatic belief that "the human" 
is supremely powerful and intelligent because no longer subject to the capricious rhythms of nature. It is common to explain human exceptionalism in terms of a break, or transcendence of our natural origins. However, as I tried to explain above, I don't think "the human" has a circumscribed identity that is easily individuated from what we perceive as outside and other than human. As the markers of what make the difference have fallen-opposable thumb, language use, brain size, forethought, upright posture and forward gaze, complex social organisation-we learn that identity is ecological through and through, a mangle of variables that inhabit and make possible (or impossible) every unique being. As I write this response I'm in self-isolation, the coronavirus my newest and most gregarious neighbour. However, the virus's ability to use my body to reproduce itself speaks of life more generally, even in this case when we are told that a virus is pure techne, lacking life. If its RNA already knows how to utilise my DNA, and if my response to the virus is already forged in cultural beliefs and lifestyle, social affluence, diet and exercise, reading habits - indeed, there isn't anything we could leave out here-then the "meeting" is already underway and the virus has a well-developed suite of literacies and strategies as a result.

In short, I think any engagement with anthropocentrism would do well to acknowledge the how of being, the ontological complicity that gives all being, all identity, even something as tiny and apparently life-less as a virus, an ecological dimension that confounds the local with/in the global. This is not to dismiss ethical and political concerns, but it is a plea to understand why restricting our analyses into yay or nay responses might inadvertently encourage the very outcomes that we most fear, and ironically, deny the intricacies of a general ecology.

\section{REFERENCES}

Barad, K. (2011). Erasers and erasures: Pinch's unfortunate "uncertainty principle." Social Studies of Science, 41(3), 443-454.

Barnwell, A. (2017). Method matters: The ethics of exclusion. In V. Kirby (Ed.), What if culture was nature all along? (pp. 26-41). Edinburgh University Press.

Butler, J. (2005). On giving an account of oneself. Fordham University Press.

Derrida, J. (1995). For the love of Lacan (B. Edwards \& A. Lecercle, Trans.). Cardozo Law Review, 16(3-4), 699-728.

Derrida, J. (2011). The beast and the sovereign (Vols. I \& II, G. Bennington, Trans.). The University of Chicago Press.

Gatens, M. (1983). A critique of the sex/gender distinction. In J. Allen \& P. Patton (Eds.), Beyond Marxism: Interventions after Marx (pp. 143-160). Interventions Publication.

Irigaray, L. (1985). Speculum of the other woman (G. C. Gill, Trans.). Cornell University Press. (Original work published 1974).

Kirby, V. (2006). Judith Butler: Live theory. Continuum.

Kirby, V. (2011). Quantum anthropologies: Life at large. Duke University Press. 
Kirby, V. (Ed.). (2017). What if culture was nature all along? Edinburgh University Press.

Kirby, V. (2018). “Un/limited Ecologies." In D. Wood, M. Fritsch, \& P. Lynes (Eds.), Eco-deconstruction: Derrida and environmental ethics (pp. 121-140). Fordham University Press.

Latour, B. (1993). We have never been modern (C. Porter, Trans.). Harvard University Press. (Original work published 1991).

Latour, B. (1999a). "Do you believe in reality?": News from the trenches of the science wars. In Pandora's hope: Essays on the reality of science studies (pp. 126-137). Harvard University Press.

Latour, B. (1999b). Circulating reference in the Amazon forest. In Pandora's hope: Essays on the reality of science studies. Harvard University Press.

Latour, B. (2003). The promises of constructivism. In D. Ihde \& E. Selinger (Eds.), Chasing technoscience: Matrix of materiality (pp. 27-46). Indiana University Press.

Latour, B. (2004). Why has critique run out of steam? From matters of fact to matters of concern. Critical Inquiry, 30(2), 225-248.

Schrader, A. (2010). Responding to Pfiesteria piscicida (the fish killer): Phantomatic ontologies, indeterminacy and responsibility in toxic microbiology. Social Studies of Science, 40(2), 275-306.

Sokal, A. D. (1996). Transgressing the boundaries: Toward a transformative hermeneutics of quantum gravity. Social Text, 46-47, 217-252.

Spivak, G. (1976). Translator's preface. In J. Derrida (Ed.), Of grammatology (pp. ix-lxxxvii). The Johns Hopkins University Press (Original work published 1967).

Wilson, E. (1999). Introduction: Somatic compliance-Feminism, biology and science. Australian Feminist Studies, 14(29), 7-18.

Open Access This chapter is licensed under the terms of the Creative Commons Attribution 4.0 International License (http://creativecommons.org/licenses/by/4.0/), which permits use, sharing, adaptation, distribution and reproduction in any medium or format, as long as you give appropriate credit to the original author(s) and the source, provide a link to the Creative Commons license and indicate if changes were made.

The images or other third party material in this chapter are included in the chapter's Creative Commons license, unless indicated otherwise in a credit line to the material. If material is not included in the chapter's Creative Commons license and your intended use is not permitted by statutory regulation or exceeds the permitted use, you will need to obtain permission directly from the copyright holder.

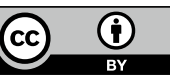

